Dopamine $\beta$-hydroxylase activities in the adrenal glands of SH rats were significantly nigher than those of normal Wistar rats. The increase in dopamine $\beta$-hydroxylase activity in the adrenal glands of SH rats may be attributed to an increase in the amount of the enzyme as in the case of tyrosine hydroxylase.

The relationship between the marked hypotensive effect of the inhibitors of tyrosine hydroxylase and dopamine $\beta$-hydroxylase and the increase in the activities of both enzymes in the adrenal glands in the case of SH rats remains a subject for future investigation.

We thank Professor K. Okamoto for spontaneously hypertensive rats and Miss Y. Nishikawa and Miss Y. Shibahara for technical assistance.

Department of Anatomy and Physiology, IKUKo NAGATSU

Aichi Prefectural College of Nursing, Moriyama-ku, Nagoya

TOSHIHARU NAGATSU Kimiko Mizutani

Department of Biochemistry,

School of Dentistry,

Aichi-Gakuin University,

Chikusa-ku, Nagoya

Hamao Umezawa

Meiki Matsuzaki

TOMIO TAKEUCHI

Institute of Microbial Chemistry,
Shinagawa-ku, Tokyo

Received August 24, 1970; revised January 5, 1971.

1 Okamoto, K., and Aoki, K., Jap. Circ. J., 27, 282 (1963).

2 Umezawa, H., Takeuchi, T., Iinuma, H., Suzuki, K., Ito, M., Matsuzaki, M., Nagatsu, T., and Tanabe, O., J. Antibiotics, 23, $514(1970)$.

${ }^{3}$ Hidaka, H., Nagatsu, T., Takeya, K., Takeuchi, T., Suda, H., Kojiri, K., Matsuzaki, M., and Umezawa, H., J. Antibiotics, 22, 228 (1969).

4 Nagatsu, T., Hidaka, H., Kuzuya, H., Takeya, K., Umezawa, H., Takeuchi, T., and Suda, H., Biochem. Pharmacol., 19, 35 (1970).

5 Nagatsu, T., Levitt, M., and Udenfriend, S., J. Biol. Chem., 239, 2910 (1964).

6 Levin, E. Y., Levenberg, B., and Kaufman, S., J. Biol. Chem., 235, 2080 (1960).

7 Nagatsu, T., van der Schoot, J. B., Levitt, M., and Udenfriend, S., J. Biochem., 64, 39 (1968).

${ }^{8}$ Kuzuya, H., and Nagatsu, T., Enzymologia, 36, 31 (1969).

9 DeQuattro, V., Nagatsu, T., Maronde, R., and Alexander, N., Circ. Res., 24, 543 (1969).

10 Ozaki, M., Jap. J. Constit. Med., 30, 155 (1967).

11 Ozaki, M., Proc. Fourth Intern. Cong. Pharmacol., 312 (1969).

\section{Purity and Stability of Synthetic Peptides such as Angiotensins and Kinins}

Now that synthetic biologically active peptides are becoming readily available, some biologists are using them without realizing that they are neither as stable nor as pure as sodium chloride.

The angiotensins are good examples. Many workers, knowing that angiotensin II sticks to glass, are careful to make up, store and use solutions in plastic containers or in siliconized glassware. We use polyethylene containers, but nevertheless dilute solutions of angiotensin II sometimes lose their potency. The inactivation is capricious and, when it occurs, may take $5 \mathrm{~min}$ or $5 \mathrm{~h}$. It can also happen as the solution passes through the tubing of an infusion pump. The inactivation is presumably due to bacterial contamination, for it is prevented by an antibacterial procedure based on that of Leary $^{1}$. It consists of filling the tubing of the infusion pumps and the polyethylene containers with a laboratory detergent such as 'Decon 75 ' overnight. After washing with distilled water for $5 \mathrm{~min}$ they are then washed with $0.01 \%$ solution (w/v) of the antiseptic chlorhexidine digluconate ('Hibitane', ICI) for $15 \mathrm{~min}$. This is followed by further washing in distilled water for $5 \mathrm{~min}$ and sterile saline for $10 \mathrm{~min}$. This treatment, which we have now used for 2 years, effectively prevents inactivation of dilute angiotensin II solutions during the course of a day's experiment.

Even more hazardous and less easy to detect is the activation of angiotensin I which can occur while the solution is being used. We have also seen activation in the tubing of infusion pumps so that, even though the reservoir contains angiotensin I, a much more active solution is delivered after passing through the pump. This activation, which may represent conversion by bacteria, is also prevented by the procedure I have outlined.

Without such antibacterial precautions, there is the strong possibility that, during an acute experiment, solutions of angiotensin II will become less active and those of angiotensin I will become more active. It is hardly necessary to stress how such changes will affect results in which conversion of angiotensin I to II is being measured by a comparison of their potencies.

Another serious hazard in the use of synthetic peptides is the presence of biologically active or inactive impurities synthesized during manufacture and not thereafter excluded. One manufacturer quotes " $>95 \%$ chemical purity" for the angiotensins and for bradykinin and its analogues. Analysis of a sample of one of these peptides, methionyl-lysyl bradykinin (A. C. Camargo, J. R. Pinto, and L. J. Greene, manuscript in preparation) shows the presence of $20 \%$ lysyl bradykinin and about $3 \%$ bradykinin. Such contamination with other biologically active substances, often with widely differing potencies, must substantially affect interpretation of comparative results. Even a $5 \%$ impurity can be important. For example, the ratio of potencies of angiotensin I and II on the rat colon preparation is about $1: 16$. A $5 \%$ contamination of the angiotensin I sample with angiotensin II will double its apparent activity.

To eliminate these problems I suggest that biologists working with peptides such as the angiotensins and bradykinins use the following procedure. (1) Prepare, store and use solutions of the peptides in conditions which minimize the possibility of bacterial contamination. We have found the antibacterial procedure described above to be adequate. The use of bacitracin has been suggested by Pickens et al. ${ }^{2}$, but addition of preservatives to solutions may introduce further biological activity ${ }^{3}$. (2) Check the solutions by bioassay both at the beginning and end of an experiment, until they are sure their precautions are adequate. (3) Perform and publish experiments to check the biological purity of the synthetic peptide. A comparison of the potencies of the angiotensins in a particular tissue or organ is more reliable when their purity is validated by effects $(a)$ on blood pressure after intravenous injection, to show the relative activity of angiotensin I after conversion to angiotensin II, and (b) on an isolated organ such as the rat uterus or rat colon, as an indication of lack of conversion of angiotensin I before use. (4) Insist that the manufacturers of the peptides define clearly and more exactly the constitution and amounts of possible contaminants in their products. These figures, together with the batch numbers, should also be published.

Department of Pharmacology,

J. R. VANE

Institute of Basic Medical Sciences,

Royal College of Surgeons of England,

Lincoln's Inn Fields,

London WC2A 3PN

Received February 11, 1971.

1 Leary, W. P., thesis, Univ. Oxford (1970).

2 Pickens, P. T., Bumpus, F. M., Lloyd, A. M., Smeby, R. R., and Page, I. H., Circulation Res., 17, 438 (1965).

${ }^{3}$ Somlyo, A. P., and Somlyo, A. V., Pharmacol. Rev., 22, 257 (1970). 